\title{
Papers
}

\section{Benign monoclonal expansion of CD8+ lymphocytes in HIV infection}

Penelope R Smith, Jamie D Cavenagh, Tim Milne, Denise Howe, Susanna J Wilkes, Paul Sinnott, Greta E Forster, Matthew Helbert

\begin{abstract}
Background-A transient expansion of the CD8+ $T$ cell pool normally occurs in the early phase of HIV infection. Persistent expansion of this pool is observed in two related settings: diffuse infiltrative lymphocytosis syndrome (DILS) and HIV associated CD8+ lymphocytosis syndrome.
\end{abstract}

Aim-To investigate a group of HIV infected patients with CD8+ lymphocytosis syndrome with particular emphasis on whether monoclonality was present.

Methods-A group of 18 patients with HIV-1 infection and persistent circulating CD8+ lymphocytosis was compared with 21 HIV positive controls. Serum samples were tested for antinuclear antibodies, antibodies to extractable nuclear antigens, immunoglobulin levels, paraproteins, human $\mathbf{T}$ lymphotropic virus type 1 (HTLV-1), Epstein-Barr virus, and cytomegalovirus serology. Lymphocyte phenotyping and HLA-DR typing was performed, and $T$ cell receptor (TCR) gene rearrangement studies used to identify monoclonal populations of $T$ cells. CD4+ and CD8+ subsets of peripheral blood lymphocytes were purified to determine whether CD8+ populations inhibited HIV replication in autologous CD4+ cells. Results-A subgroup of patients with HIV-1 infection was found to have expanded populations of CD8+ $T$ cell large granular lymphocytes persisting for 6 to 30 months. The consensus immunophenotype was CD4- CD8+ DR ${ }^{\text {high }}$ CD11a+ CD11c+ CD16- CD28 \pm CD56- CD57+, consistent with typical $T$ cell large granular lymphocytes expressing cellular activation markers. Despite the finding of monoclonal TCR gene usage in five of 18 patients, there is evidence that the $\mathrm{CD} 8+$ expansions are reactive populations capable of mediating non-cytotoxic inhibition of HIV replication.

Conclusions-A subgroup of HIV positive patients has CD8+ lymphocytosis, but despite the frequent occurrence of monoclonal TCR gene usage there is evidence that this represents an immune response to viral infection rather than a malignant disorder.

(F Clin Pathol 2000;53:177-181)

Keywords: HIV infection; CD8+ lymphocytosis; clonality

Infection with HIV causes a progressive depletion of CD4+ $\mathrm{T}$ cells and subsequent immune deficiency, developing at variable rates in individual patients. The CD8+ T cell population is expanded in early HIV infection as part of the host immune response to the virus. ${ }^{1}$ This response is generally not sustained and is followed by a subsequent decline in $\mathrm{CD} 8+\mathrm{T}$ cell numbers. $^{23}$

B cell lymphomas are found commonly in patients with HIV infection, while $\mathrm{T}$ cell malignancy is extremely uncommon. However, there are two clinical settings in which expansion of the CD8+ $\mathrm{T}$ cell population has been identified in association with HIV infection: the first is HIV associated CD8+ lymphocytosis syndrome and the second is diffuse infiltrative lymphocytosis syndrome (DILS), a syndrome which may represent a subgroup of the former. DILS is characterised by the sequestration of CD8+ T cells in the salivary glands, lungs, kidneys, and other visceral sites $^{4-6}$ and clinically resembles Sjögren's syndrome, although characteristically autoantibodies such as antinuclear antibodies (ANA), anti-Ro, and anti-La are absent. DILS patients have an increased frequency of certain major histocompatibility complex (MHC) class II alleles: HLA-DRB1 ${ }^{\star} 1301$ among blacks and Europids and HLA-DRB1 1102 among blacks only. ${ }^{48}$ This finding is consistent with the hypothesis that DILS is a florid immune response to HIV infection, restricted by the ability of specific MHC alleles to present HIV peptides to the T cell receptor (TCR).

Examination of the peripheral blood in patients with DILS has shown CD8+ $\mathrm{T}$ cell populations consisting primarily of a memory/ effector phenotype, characterised by increased CD57 expression along with the cell adhesion molecules CD11a/CD18 and CD29. ${ }^{9}$ In T cells infiltrating the salivary glands of HIV positive individuals with DILS, TCR $\beta$ usage is restricted. $^{7}$ There is preferential usage of certain non-germline amino acids at position
Accepted for publication 31 August 1999 
97 in the third complementarity determining region, a position thought to confer antigenic specificity, suggesting that this is an antigen driven response. A similar finding has been made in infants, ${ }^{10}$ where persistent and monoclonal expansions of CD8+ lymphocyte subpopulations bearing distinct $\mathrm{V} \alpha / \mathrm{V} \beta$ gene products are observed, and may act as negative determinants of HIV disease progression following vertical transmission. These findings support the notion that HIV associated CD8+ lymphocytosis is an antigenically driven immune host response.

CD8+ lymphocytosis is also seen in HIV+ individuals without the full clinical picture of DILS and may be associated with an improved long term prognosis, defined by the presence for at least three months of at least $1.5 \times$ $10^{9} /$ litre CD8+ T cells. ${ }^{11}$

We have investigated a group of HIV infected patients with persistent circulating CD8+ lymphocytosis. Our aim was to determine the immunophenotype of these expanded populations and to explore the relation of this syndrome with the better described DILS clinical phenotype. We were particularly interested in the clonality of these expanded $\mathrm{T}$ cell populations and whether antiviral activity could be demonstrated.

\section{Methods}

PATIENTS

Patients with HIV-1 infection and persistent circulating CD8+ lymphocytosis were compared with a group of $21 \mathrm{HIV}$ positive controls matched by age, sex, route of transmission, and ethnic origin in July 1998. The patients attended the Grahame Hayton Unit at the Royal London Hospital with HIV infection diagnosed by enzyme linked immunosorbent assay (ELISA) and western blot analysis. Case records of all 432 patients were reviewed and of these, 20 were found to have CD8+ lymphocytosis, defined as a CD8+ count of greater than $1.5 \times 10^{9} /$ litre persisting for more than three months. One patient was excluded from the study owing to active hepatitis B infection, which is a well recognised cause of pre-existing CD8+ lymphocytosis. Other exclusion criteria included known HIV seroconversion within the previous three months.

Informed consent was obtained, according to the procedure laid down by the institution's ethics committee, from 18 of the patients who were suitable for study. Those with CD8+ lymphocytosis were evaluated for the presence of sicca symptoms including a Schirmer's test, and a physical examination was carried out to identify the presence of parotid gland enlargement. Blood samples were collected on enrolment and where possible serological data were obtained from medical records, along with details of antiretroviral treatment.

SEROLOGICAL STUDIES

All patients underwent testing for ANA by indirect immunofluorescence and antibodies against extractable nuclear antigens (ENA) by gel diffusion. Serum samples were tested for immunoglobulin levels and the presence of paraproteins. Twelve of the 18 patients with CD8+ lymphocytosis consented to HTLV-1 testing, which was carried out using a passive particle agglutination test to detect antibodies to HTLV-1. Epstein-Barr virus (EBV) VCA IgG was performed on all patients from stored serum samples. Serological data obtained from medical records included hepatitis B and C serology and testing for the presence of cytomegalovirus (CMV) IgG antibody.

LYMPHOCYTE PHENOTYPIC ANALYSIS

Peripheral blood lymphocyte subsets were analysed in all patients by flow cytometry on lysed whole blood.

\section{HLA TYPING}

HLA typing for DRB was performed on 17 patients with CD8+ lymphocytosis and the matched control group of 21 HIV positive individuals using sequence specific primers.

TCR GENE REARRANGEMENT STUDIES

Peripheral blood samples were collected in EDTA on all patients. Following DNA extraction, single stranded conformation polymorphism polymerase chain reaction was used to analyse TCR $\gamma$ gene rearrangements. This technique is required because of the limited combinatorial diversity of the TCR $\gamma$ locus, as it detects variations in both sequence and size of amplified DNA. ${ }^{12}$

p24 INHIBITION STUDIES

Inhibition studies of $\mathrm{p} 24$, an HIV core protein, were performed to determine whether CD8+ populations could inhibit HIV replication in autologous CD4+ cells. These studies were performed on two control group patients and five patients with high circulating levels of $\mathrm{CD} 8+\mathrm{T}$ cells. Peripheral blood lymphocytes were density separated and monocytes removed by adhesion. $\mathrm{B}$ and $\mathrm{CD} 8+\mathrm{T}$ cells were removed using magnetic beads. The remaining CD4+ $\mathrm{T}$ cells were resuspended at $10 \% \mathrm{ml}$ in RPMI, $10 \%$ autologous serum, and antibiotics. CD8+ T cells were then added back to $\mathrm{CD} 4+\mathrm{T}$ cells at proportions of $0 \%, 6.25 \%, 25 \%$, or $50 \%$. The CD4+/CD8+ mixtures were stimulated with PHA $5 \mu \mathrm{g} / \mathrm{ml}$ for eight days. Supernatant was harvested and the p24 concentration determined by ELISA (Coulter). ${ }^{13}$

STATISTICAL ANALYSIS

Statistical analysis included descriptive statistics of the study population, and the MannWhitney U test was used where continuous data were not normally distributed. These tests of significance were two tailed. Categorical data were compared using the $\chi^{2}$ test. The level of significance was set at $\mathrm{p}<0.05$.

\section{Results}

\section{PATIENTS}

The median age of the control group was 32 years, and that of the CD8+ lymphocytosis group 40.5 years (table 1 ). The observed duration of continuous CD8+ lymphocytosis was six to 30 months. In the CD8+ lymphocytosis group, two of the 18 patients complained of 
sicca symptoms requiring artificial tears, though Schirmer's test was negative in both. There was no clinical evidence of parotid gland enlargement, splenomegaly, or neutropenia in either patient group. From the CD8+ lymphocytosis group, 15 of the 18 patients $(83.3 \%)$ were taking combination antiretroviral treatment, as were 17 of the 21 patients from the control group $(81.0 \%)$. Patients with CD8+ lymphocytosis had been infected with HIV-1 for significantly longer than controls at time of entry to the study. The median HIV-1 RNA viral load was slightly lower in the CD8+ lymphocytosis group $(\mathrm{p}=0.4, \mathrm{NS})$.

LYMPHOCYTE PHENOTYPIC ANALYSIS

The consensus immunophenotype of the CD8+ $\mathrm{T}$ cells was CD3+ CD4- CD8+ Dr ${ }^{\text {high }}$ CD11a+ CD11c+ CD16- CD28 \pm CD56CD57+ (table 1). This is the expected immunophenotype of $\mathrm{T}$ cell large granular lymphocytes as seen on peripheral blood smears (fig 1), and the enhanced DR expression is suggestive of cellular activation.

TCR GENE REARRANGEMENT STUDIES

Clonal analysis results are shown in table 1 . Five patients from the CD8+ lymphocytosis group had monoclonal $\mathrm{T}$ cell populations, of whom two also had paraproteins. All five of these patients were taking antiretroviral treatment at this time.

SEROLOGICAL AND HLA STUDIES

None of the patients tested had antibodies against HTLV-1 or hepatitis C virus, and all patients tested were positive for CMV IgG

Table 1 Demographic data, dual immunophenotyping studies, presence of paraproteins, and TCR gene rearrangement results in control and CD8+ lymphocytosis groups

\begin{tabular}{|c|c|c|}
\hline & $\begin{array}{l}\text { Controls } \\
(n=21)\end{array}$ & $\begin{array}{l}\text { CD8+ lymphocytosis } \\
(n=18)\end{array}$ \\
\hline Age range (years) & 20 to 55 & 30 to 58 \\
\hline \multicolumn{3}{|l|}{ Race } \\
\hline Europid & 17 & 14 \\
\hline Black African & 2 & 4 \\
\hline Asian & 2 & 0 \\
\hline \multicolumn{3}{|l|}{ Mode of transmission } \\
\hline Male to male & 18 & 14 \\
\hline Heterosexual & 3 & 4 \\
\hline \multicolumn{3}{|l|}{ Sex } \\
\hline Male & 20 & 14 \\
\hline Female & 1 & 4 \\
\hline \multicolumn{3}{|l|}{ CDC category } \\
\hline A & 5 & 4 \\
\hline $\mathrm{B}$ & 12 & 11 \\
\hline C & 4 & 3 \\
\hline Median time since diagnosis (years) & 4.5 & $8.0^{\star}$ \\
\hline No of patients taking antiretroviral treatment & $17(81.0 \%)$ & $15(83.3 \%)$ \\
\hline Median HIV-1 RNA viral load (copies/ml) & 3511 & $1172 \dagger$ \\
\hline Paraproteins & 0 & $\begin{array}{l}2 \\
\text { (Patient No 1, IgG and IgM) } \\
\text { (Patient No 2, IgG) }\end{array}$ \\
\hline Median IgG level (g/litre) & 15.8 & $17.25 \ddagger$ \\
\hline \multicolumn{3}{|c|}{ Lymphocyte phenotype double positive (mean $\%$ of $\mathrm{T}$ cells) } \\
\hline CD8+/DR+ & 35.7 & 63.2 \\
\hline $\mathrm{CD} 8+/ \mathrm{CD} 11 \mathrm{a}+$ & 63.7 & 80.6 \\
\hline CD8+/CD11c+ & 10.0 & 14.8 \\
\hline CD8+/CD28+ & 23.0 & 18.4 \\
\hline CD8+/CD57+ & 26.5 & 28.2 \\
\hline EBV VCA IgG positive (No of patients) & $14(66.7 \%)$ & $13(72.2 \%)$ \\
\hline \multicolumn{3}{|l|}{ TCR gene rearrangement $\uparrow$} \\
\hline Polyclonal & 17 & 13 \\
\hline Oligoclonal & 4 & 0 \\
\hline Monoclonal & 0 & 5 \\
\hline
\end{tabular}

${ }^{\star} \mathrm{p}=0.0007$, Mann-Whitney U test.

$\mathrm{t} \mathrm{p}=0.4$, Mann-Whitney U test.

$\ddagger \mathrm{p}=0.23, \chi^{2}$ (normal range $\mathrm{IgG}<16 \mathrm{~g} / \mathrm{l}$ )

$\uparrow \mathrm{p}=0.009, \chi^{2}$.

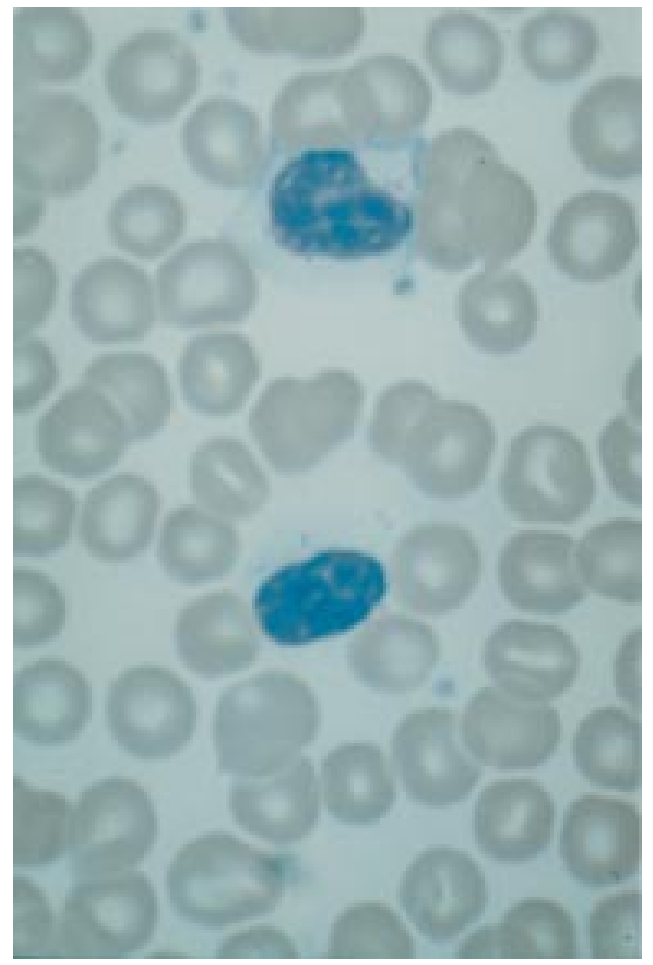

Figure 1 Peripheral blood film showing T cell large granular lymphocytes in a patient with CD8+ granular lymphocytes
lymphocytosis $(\times 270)$.

within both groups. ANA was weakly positive at $1: 80$ in three of the 18 patients with CD8+ lymphocytosis two of the 21 controls, all corresponding to a homogeneous pattern. Anti-Ro and anti-La antibodies were not detected in either patient group. The median total IgG level was slightly higher in the CD8+ lymphocytosis group (table 1); however, this difference did not reach statistical significance. The HLA alleles linked to DILS were seen more often in controls (DRB $1^{\star} 11+, 8 / 21$; $\left.\mathrm{DRB} 1{ }^{\star} 13+, 6 / 21\right)$ than in patients with CD8+ lymphocytosis $\left(\mathrm{DRB} 1{ }^{\star} 11+, 3 / 17\right.$; DRB $1^{\star} 13+$, 1/17).

p24 INHIBITION STUDIES

A reduction in $\mathrm{p} 24$ production occurred when different proportions of CD8 $+\mathrm{T}$ cells were added back to purified CD4+ T cells (fig 2 ) in one control and one patient with CD8+ lymphocytosis. This shows that on a cell to cell basis, CD8+ T cells inhibit HIV replication, whether they arise from HIV infected patients with or without CD8+ lymphocytosis. Phytohaemaglutinin stimulation in the remaining patients did not result in p24 production, as is often the case in this particular setting. ${ }^{14}$

\section{Discussion}

This group of patients with persistent CD8+ lymphocytosis is clearly distinct from those patients with DILS who have been reported previously. The former group did not show a preferential association with certain HLA alleles or parotid gland enlargement and, with the exception of two patients, sicca symptoms were not a prominent feature. There is evidence that CD8+ lymphocytosis occurring in association 
p24 INHIBITION STUDIES

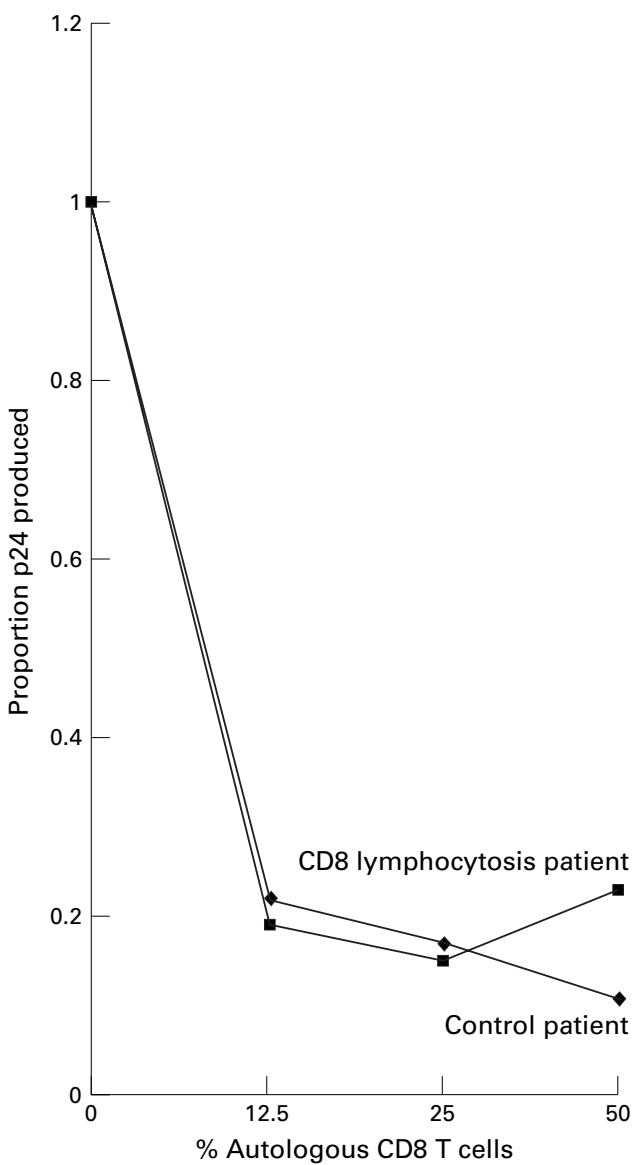

Figure 2 Proportion of $p 24$ produced against percentage of $C D 8+T$ cells. As autologous $C D 8+T$ cells are reintroduced to CD4+ T cells in increasing concentrations, $p 24$ production is inhibited. (Results from a single representative experiment.)

with DILS represents an antigenically driven immune response which is associated with a slow progression of HIV disease. ${ }^{89} \mathrm{CD} 8+$ lymphocytosis may be a part of the spectrum of this syndrome, and its presence should alert the clinician to the possibility of the presence of visceral infiltration by CD8 lymphocytes.

Although there are previous reports of non-DILS CD8+ T cell expansions occurring in the setting of HIV infection, our series adds considerably to the reported number of cases of HIV associated CD8+ lymphocytosis where a monoclonal TCR gene rearrangement has been detected. In an analysis of 2365 HIV positive individuals, CD8+ lymphocytosis was detected in only eight cases, and all of these were found to have polyclonal TCR $\beta$ chain rearrangements. ${ }^{15}$ Furthermore, all eight patients had undergone a splenectomy following abdominal trauma and it is well known that lymphocytosis is a frequent post-splenectomy finding. In a more recent case report, ${ }^{16}$ a monoclonal expansion of $\mathrm{T}$ cell large granular lymphocytes, as determined by TCR gene rearrangement studies in a splenectomised HIV positive patient, was interpreted as indicating a $\mathrm{T}$ cell leukaemia, although no clinical evidence of malignancy was described other than lymphocytosis. Similarly, none of the patients that we report has shown clinical evidence of malignancy on follow up to 12 months, and in some instances the CD8+ counts fell after a period of antiretroviral treatment (data not shown). Five patients from the CD8+ lymphocytosis group were shown to have monoclonal $\mathrm{T}$ cell populations; all the patients in this subgroup were on antiretroviral treatment at the time this study was carried out. This subgroup included two female black African patients with paraproteins. These women underwent a bone marrow examination which showed increased lymphocytes but no evidence of malignancy, and an abdominal ultrasound scan which did not show hepatosplenomegaly or lymphadenopathy. Urinary free light chains were not detected in either of these patients.

Similar small monoclonal CD8+ $\mathrm{T}$ cell populations have also been seen in normal elderly individuals and in infants with HIV infection, ${ }^{10}{ }^{17}$ and a larger transient proliferation of CD8+ $\mathrm{T}$ cells with monoclonal gene rearrangement of the TCR V $\beta$ locus has been described in acute viral hepatitis. ${ }^{18}$ Oligoclonal patterns of TCR gene rearrangements have also been reported in patients with acute EBV induced infectious mononucleosis. ${ }^{19}$ We conclude that, despite the presence of monoclonal TCR gene rearrangements, there is no additional evidence to suggest the presence of a malignant process in this group of patients with monoclonal TCR gene rearrangements. Rather, our findings support the important general point that clonality itself is not necessarily indicative of malignancy.

In our group of patients B cell activation is evident. Patients with the highest CD8+ T cell numbers were more likely to have monoclonal $\mathrm{T}$ cell populations and tended to have the highest immunoglobulin levels, along with detectable paraproteins in two cases, suggesting that common factors drive both $\mathrm{T}$ cell and B cell expansions. There was no correlation between immunoglobulin levels and previous exposure to EBV or CMV, and it can be seen that although median duration of HIV infection was significantly longer in those with CD8+ lymphocytosis than in controls, the groups were otherwise similar. Therefore, although oligoclonal and clonal $\mathrm{T}$ cell expansions quite commonly occur during immune responses, we were unable to correlate CD8+ $\mathrm{T}$ cell expansions in HIV infected patients with any other common viral infection.

In this group of patients the expanded populations have the phenotype CD8+ DR+ LFA1+ CD28 \pm , which is certainly not typical of $\mathrm{T}$ cell malignancies. The CD8 $+\mathrm{T}$ cells in this group appear to be reactive, as suggested by their high DR expression. Furthermore there is evidence that the CD8+ T cells in our patients inhibit HIV replication. The expanded CD8+ population may therefore represent an attempt to restore reactivity to HIV. CD8+ $\mathrm{T}$ cell mediated suppression of HIV replication measured in the same way in early perinatal HIV infection has potent effects on viral load and survival. ${ }^{20}$ There is circumstantial evidence to suggest that the expanded 
CD8+ $\mathrm{T}$ cell numbers in HIV associated CD8+ lymphocytosis syndrome are involved in an immune response directed at an antigen derived from HIV itself. It has been reported that this process may be partly mediated by a soluble lymphokine, acting in a bystander fashion. ${ }^{21}$

Although it was previously thought that most of the cells contributing to a virally induced lymphocytosis are bystanders, studies in murine models have shown that large numbers of such cells are specific for viral peptides. ${ }^{22}$ Since precursor cells for specific peptides are rare, a brisk $10^{5}$-fold expansion of responding cells is required to explain these findings. New $\mathrm{MHC} /$ tetramer technology suggests that a high frequency of HIV responding $\mathrm{T}$ cells is common in infected individuals. ${ }^{23}$ Therefore it is not unexpected that this process may sometimes result in detectable monoclonal CD8+ T cell populations. Patients with CD8+ lymphocytosis show CD8+ T cells with functional activity against HIV, and we have failed to detect other sources of antigenic drive. Taken together, these findings suggest that HIV itself may be the responsible antigen that drives the observed CD8 $+\mathrm{T}$ cell expansions seen in this setting.

Monoclonal $\mathrm{T}$ cell populations are known to exist in various situations, both in normal and immunocompromised individuals. We have found evidence of monoclonal $\mathrm{T}$ cell expansions in HIV positive patients with CD8 lymphocytosis syndrome, but not in HIV positive individuals without CD8 lymphocytosis. Various features of these cases indicate that the CD8+ $T$ cells are reactive and may indeed represent a florid immune response to HIV related antigens. There has been no clinical evidence of malignancy in any of these patients, and the CD8+ count has been observed to fall in some instances following antiretroviral treatment. CD8+ lymphocytosis has previously been linked to DILS, although our patients have a distinct clinical, HLA, and immunophenotypic profile. This group of patients shows that monoclonal $\mathrm{T}$ cell expansions occur in HIV but may not indicate malignancy. Long term clinical follow up of this group of patients is required to monitor for evidence of malignant transformation and to derive prognostic information on progression of HIV disease.

We wish to acknowledge the involvement of Dr V Ramasubramanian in the initial stages of this study. We thank Mr Dhanraj Girdhar from the Virology Department, St Bartholomew's Girdhar from the Virology Department, St Bartholomew's Hospital, for carrying out EBV VCA IgG testing and Susan
Davey from the Tissue Typing Laboratory, Royal London Hospital, for her involvement with the HLA-DR typing. Denise pital, for her involvement with the HLA-DR typing. Denise
Howe was supported by the Musgrove Leukaemic Group, Somerset, UK.
1 Brugnoni D, Prati E, Cattaneo R, et al. The primary response to HIV infection is characterized by an expansion of activated CD8+ CD28- cells. AIDS 1996;10:104-6.

2 Roos MTL, Lange JMA, De Geode REY, et al. Virus phenotype and immune response in primary human immunodeficiency virus type 1 (HIV-1) infection. F Infect Dis 1992;165:427-32.

3 Livingstone WJ, Moore M, Simmonds P, et al. Frequent nfection of peripheral blood CD8-positive T-lymphocytes with HIV-1. Lancet 1996:348:649-54.

4 Itescu S, Bracato LJ, Buxbaum J, et al. A diffuse infiltrative CD8 lymphocytosis syndrome in human immunodeficiency virus (HIV) infection: a host immune response associated with HLA-DR5. Ann Intern Med 1990;112:310 .

5 Kazi S, Cohen PR, Reveille JD, et al. The diffuse infiltrative lymphocytosis syndrome: clinical and immunogenetic lymphocytosis syndrome: clinical and imm

6 Moulignier A, Authier FJ, Baudrimont M, et al. Peripheral neuropathy in human immunodeficiency virus-infected patients with the diffuse infiltrative lymphocytosis syndrome. Ann Neurol 1997;41:438-45.

7 Dwyer E, Itescu S, Winchester R. Characterization of the primary structure of $T$ cell receptor $\beta$ chains in cells nfiltrating the salivary gland in the sicca syndrome of HIV-1 infection. $\mathcal{F}$ Clin Invest 1993;92:495-502.

8 Itescu S, Rose S, Dwyer E, et al. Certain HLA-DR5 and-DR6 major histocompatibility complex class II alleles are associated with a CD8 lymphocytic host response to human immunodeficiency virus type 1 characterized by low lymphocyte viral strain heterogeneity and slow disease progression. Proc Natl Acad Sci USA 1994;91:11472-6.

9 Itescu S, Dalton J, Zhang HZ, et al. Tissue infiltration in a CD8 lymphocytosis syndrome associated with human immunodeficiency virus-1 infection has the phenotypic appearance of an antigenically driven response. f Clin Invest 1993;91:2216-25.

10 Halapi E, Gigliotti D, Hodara V, et al. Detection of CD8 T cell expansions with restricted T cell receptor V gene usage in infants vertically infected by HIV-1. AIDS 1996;10: 1621-6.

11 Constans J, Ladner J, Dabis F, et al. Hyperlymphocytose CD8 au cours de l'infection par le VIH:63 observations. Presse Med 1992;21:27-30.

12 Lynas C, Howe D. Simple, reliable detection of T cell clones by PCR-LIS-SSCP analysis of TCR $\gamma$ rearrangement. $\mathrm{Mol}$ Cell Probes 1998;12:41-8.

13 Brinchmann JE, Gaudernack G, Vartdal F. CD8+ T cells inhibit HIV replication in naturally infected CD4+ T cells. F Immunol 1990;144:2961-6.

14 Alouf JE, Geoffroy C, Montagnier L, et al. High production of the acquired immunodeficiency syndrome virus of the acquired immunodeficiency syndrome virus
(lymphadenopathy- associated virus) by human $\mathrm{T}$ lymphocytes stimulated by streptococcal mitogenic toxins. $\mathcal{F}$ phocytes stimulated by streptoco

15 Zambello R, Trentin L, Agostini C, et al. Persistent polyclonal lymphocytosis in human immunodeficiency virus-1 infected patients. Blood 1993;81:3015-21.

6 Pulik M, Lionnet F, Fourcade C, et al. $\mathrm{CD}^{+} \mathrm{CD} 8^{+} \mathrm{CD} 56^{-}$ clonal large granular lymphocyte leukaemia and HIV infection. Br f Haematol 1997;98:444-5.

17 Schwab R, Szabo P, Manavalan JS, et al. Expanded CD4+ and CD8+ T cell clones in elderly humans. F Immunol 1997;158:4493-9.

18 Nakahara K, Utsunomiya A, Hanada S, et al. Transient appearance of CD3+CD8+ T lymphocytes with monoclonal gene rearrangement of the $\mathrm{T}$ cell receptor $\beta$ locus. $\mathrm{Br}$ flonal gene rearrangement of $1998 ; 100: 411-14$

19 Strickler JG, Movahed LA, Gajl-Peczalska KJ, et al. Oligoclonal $\mathrm{T}$ cell receptor gene rearrangement in blood lymphocytes of patients with acute Epstein-Barr virusinduced infectious mononucleosis. F Clin Invest 1990;86: 1358-63.

20 Pollack H, Zhan M-X, Safrit JT, et al. CD8+ T cell-mediated suppression of HIV replication in the first year of life: association with lower viral load and favorable early survival. AIDS 1997;11:F9-13.

21 Walker CM, Levy JA. A diffusible lymphokine produced by CD8+ T lymphocytes suppresses HIV replication. Immunology 1989;66:628-30.

22 Murali-Krishna K, Altman JD, Suresh M, et al. Counting antigen-specific CD8 T cells: a reevaluation of bystander activation during viral infection. Immunity 1998;8:177-87.

23 Gray CM, Lawrence J, Schapiro JM, et al. Frequency of Gray CM, Lawrence J, Schapiro JM, et al. Frequency
class I HLA-restricted anti-HIV CD8 + T cells in individuals receiving highly active antiretroviral therapy (HAART) f Immunol 1999;162:1780-8. 